Advances in Intelligent Systems and Computing 1189

Manoj Kumar Sharma

Vijay Pal Singh Dhaka

Thinagaran Perumal · Nilanjan Dey

João Manuel R. S. Tavares Editors

Innovations in Computational Intelligence and Computer Vision

Proceedings of ICICV 2020

黑 Springer

XX, 580 p. 70 illus.

Printed book

Softcover

Ca. 219,99 € | Ca. £199.99 | Ca.

$\$ 279.99$

${ }^{[1]}$ Ca. $235,39 €(D) \mid$ Ca. $241,99 €(A)$

| Ca. CHF 259,50

eBook

Available from your library or

springer.com/shop

MyCopy [3]

Printed eBook for just

$€ \mid \$ 24.99$

springer.com/mycopy
M.K. Sharma, V.P.S. Dhaka, T. Perumal, N. Dey, J.M.R.S. Tavares (Eds.)

\section{Innovations in \\ Computational Intelligence and Computer Vision}

Proceedings of ICICV 2020

Series: Advances in Intelligent Systems and Computing

- Presents selected works by active researchers in the fields of computational intelligence and computer vision

- Gathers the outcomes of the ICICV 2020, hosted by Manipal University Jaipur, Rajasthan, India

- Serves as a reference guide for researchers and practitioners in academia and industry

This book presents high-quality, peer-reviewed papers from the International Conference on "Innovations in Computational Intelligence and Computer Vision (ICICV 2020)," hosted by Manipal University Jaipur, Rajasthan, India, on January 17-19, 2020. Offering a collection of innovative ideas from researchers, scientists, academics, industry professionals and students, the book covers a variety of topics, such as artificial intelligence and computer vision, image processing and video analysis, applications and services of artificial intelligence and computer vision, interdisciplinary areas combining artificial intelligence and computer vision, and other innovative practices.
Order online at springer.com / or for the Americas call (toll free) 1-800-SPRINGER /

or email us at: customerservice@springernature.com. / For outside the Americas call +49 (0) 6221-345-4301 / or email us at: customerservice@springernature.com.

The first $€$ price and the $£$ and $\$$ price are net prices, subject to local VAT. Prices indicated with [1] include VAT for books; the $€(D)$ includes $7 \%$ for Germany, the $€(A)$ includes $10 \%$ for Austria. Prices indicated with [2] include VAT for electronic products; $19 \%$ for Germany, $20 \%$ for Austria. All prices exclusive of carriage charges. Prices and other details are subject to change without notice. All errors and omissions excepted. [3] No discount for MyCopy. 